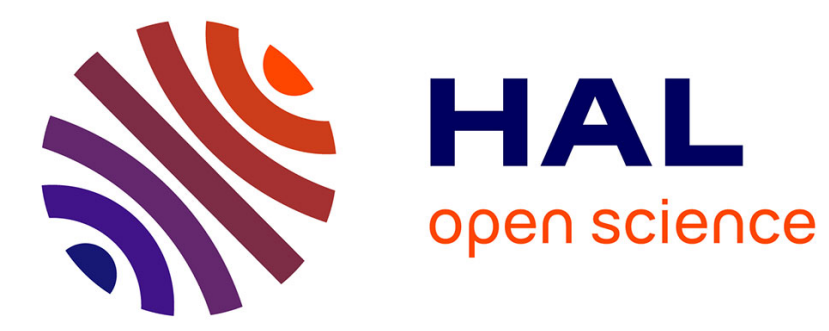

\title{
A coordinated set of ecosystem research platforms open to international research in ecotoxicology, AnaEE-France
} Christian Mougin, Didier Azam, Thierry Caquet, Nathalie Cheviron, Samuel

Dequiedt, Jean-François Le Gaillard, Olivier Guillaume, Sabine Houot, Gérard Lacroix, Francois Lafolie, et al.

\section{To cite this version:}

Christian Mougin, Didier Azam, Thierry Caquet, Nathalie Cheviron, Samuel Dequiedt, et al.. A coordinated set of ecosystem research platforms open to international research in ecotoxicology, AnaEEFrance. SETAC Europe 26. Annual Meeting, May 2016, Nantes, France. 394 p. hal-02742764

\section{HAL Id: hal-02742764 \\ https://hal.inrae.fr/hal-02742764}

Submitted on 3 Jun 2020

HAL is a multi-disciplinary open access archive for the deposit and dissemination of scientific research documents, whether they are published or not. The documents may come from teaching and research institutions in France or abroad, or from public or private research centers.
L'archive ouverte pluridisciplinaire HAL, est destinée au dépôt et à la diffusion de documents scientifiques de niveau recherche, publiés ou non, émanant des établissements d'enseignement et de recherche français ou étrangers, des laboratoires publics ou privés. 


\title{
A coordinated set of ecosystem research platforms open to international research in ecotoxicology, AnaEE-France
}

\author{
Christian Mougin ${ }^{1}$, Didier Azam ${ }^{2}$, Thierry Caquet ${ }^{3}$, Nathalie Cheviron ${ }^{1}$, Samuel Dequiedt ${ }^{4}$, \\ Jean-François Le Galliard ${ }^{5}$, Olivier Guillaume ${ }^{6}$, Sabine Houot ${ }^{7}$, Gérard Lacroix ${ }^{5}$, François \\ Lafolie $^{8}$, Pierre-Alain Maron ${ }^{4}$, Radika Michniewicz ${ }^{6}$, Christian Pichot ${ }^{9}$, Lionel Ranjard ${ }^{4}$, \\ Jacques Roy ${ }^{10}$, Bernd Zeller ${ }^{11}$, Jean Clobert $^{6}$, André Chanzy ${ }^{8}$

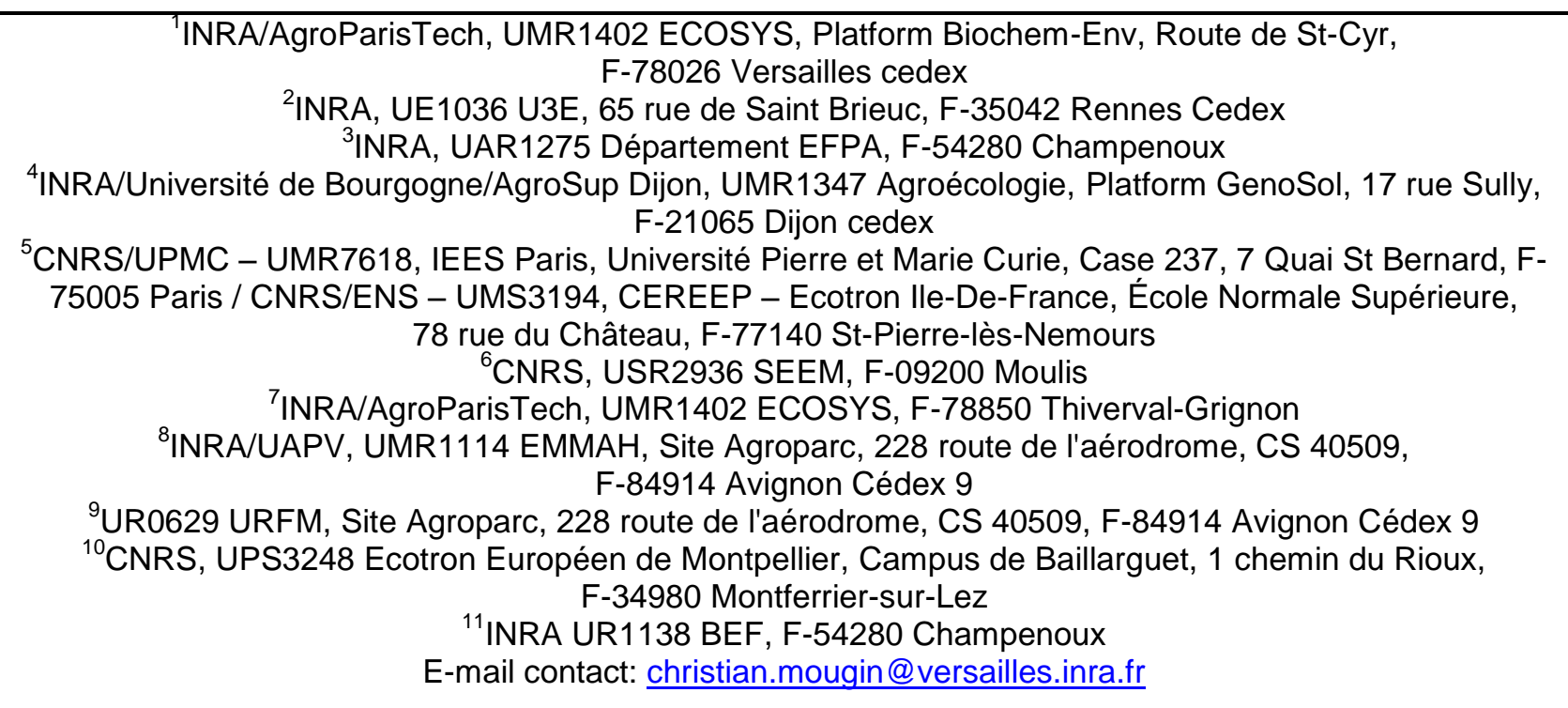

\section{Introduction}

Human activities have altered continental ecosystems worldwide and generated a major environmental crisis. To truly develop integrative ecosystem biology and to assess the consequences of various forcing factors, such as pollutions, we therefore need new approaches and tools that bridge the traditional gap between life and environmental sciences.

To deal with that challenge, the infrastructure for Analysis and Experimentation on Ecosystems (AnaEEFrance) is an integrated network of the major French experimental, analytical and modeling platforms dedicated to the biological study of continental ecosystems, both aquatic and terrestrial [1].

\section{The relevance of AnaEE-France platforms for research in ecotoxicology}

AnaEE-France comprises five complementary nodes offering access to the best experimental facilities and associated biological resources and data (Figure 1).

Ecotrons could allow testing the effects of toxicants under realistic physical, chemical and biological conditions, including both aquatic and terrestrial ecosystems with a significant number of species representative of complex biological communities (Node 1).

Several experimental platforms allow experimentation in semi-natural conditions, in which environmental factors can be realistically manipulated (Node 2). They provide powerful tools to link small-scale laboratory experiments including a single or a few species only or ex natura experiments to field or in natura experiments.

More than twenty in natura experimental sites cover a range of continental ecosystems (forests, grasslands, crops, aquatic systems) with the aims of harmonizing measurement protocols and data management as well as promoting site and data access (Node 3). They host long-term manipulations spanning several decades where it is possible to take into account ecosystem inertia and feedback loops than cannot be detected on the short term in Ecotrons or semi-natural platforms. 
AnaEE-France also provides shared instruments and analytical platforms dedicated to environmental (micro)-biology, as well as a mobile laboratory (Node 4). They develop efficient devices offering rapid and/or high throughput characterization of samples from experimental sites and environmental survey networks by accessing to cutting edge equipment.

AnaEE-France provides users with data bases and modeling tools designed to represent ecosystem dynamics and to go further in coupling ecological, agronomical and evolutionary approaches (Node 5). Covering a large area of experimental, analytical or modelling platforms as well as databases, the infrastructure has to face the challenge of managing dispersed and heterogeneous information from various disciplines including ecotoxicology.

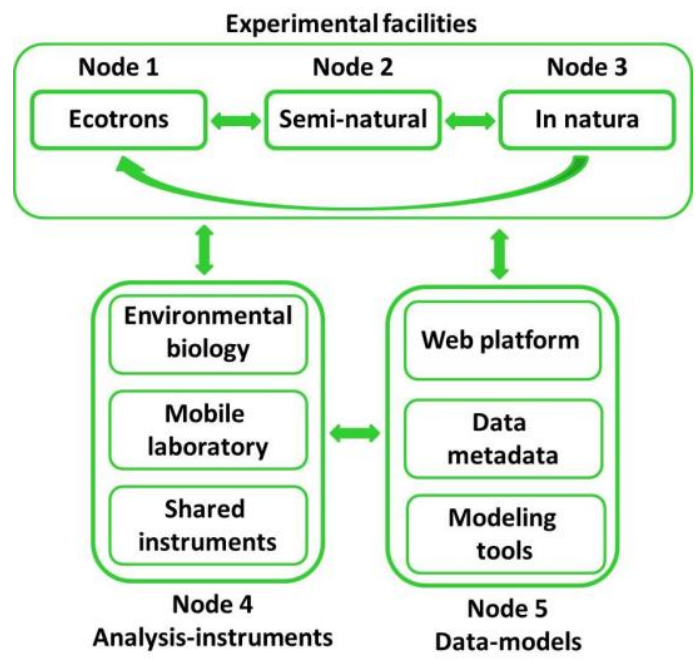

Figure 1: Scheme of AnaEE-France illustrating the functional relationships between each node.

The Ecotrons (Montpellier and lle de France), the PEARL (Rennes) and PLANAQUA (Foljuif) mesocosms, the observatory SOERE PRO (several sites in France), the mobile laboratory M-POETE (Champenoux), the analytical platforms GenoSol (Dijon), Biochem-Env (Versailles) and MRI (Moulis), the modeling platforms Record, Vsoil and Capsis are the main services of AnaEE-France open to the research in ecotoxicology.

\section{Conclusions}

AnaEE-France offers to the international community of environmental scientists, and notably ecotoxicologists, a coherent set of coordinated platforms (semi-natural and in natura services, analytical platforms, data management and modelling resources) and efficient methods for their optimized management and functioning. The platforms of AnaEE-France are closely associated to research laboratories from French research institutes or universities that host relevant practical and scientific skills. They have deployed quality management systems based on internal referential of their hosting institutions (CNRS and INRA). Some of them are engaged into the ISO 9001 standardization. GenoSol and BiochemEnv possess French permission to import and perform experiments on Quarantine Material (soils, living organisms...). The platforms have accepted principles of ethical and professional conduct, especially if the research involves animals.

AnaEE-France was designed in line of AnaEE-Europe Infrastructure concept, which is currently on the ESFRI roadmap under preparation phase.

\section{References}

[1] Mougin C, Azam D, Caquet T, Cheviron N, Dequiedt S, Le Galliard JF, Guillaume O, Houot S, Lacroix G, Lafolie F, Maron PA, Michniewicz R, Pichot C, Ranjard L, Roy J, Zeller B, Clobert J, Chanzy A. 2015. A coordinated set of ecosystem research platforms open to international research in ecotoxicology, AnaEEFrance. Environ Sci Pollut Res 22(20):16215-16228. DOI 10.1007/s11356-015-5233-9

Acknowledgement - AnaEE-France is an infrastructure of the French Investments for the Future ("Investissements d'Avenir") programme, overseen by the French National Research Agency (ANR) (ANR11-INBS-0001). 